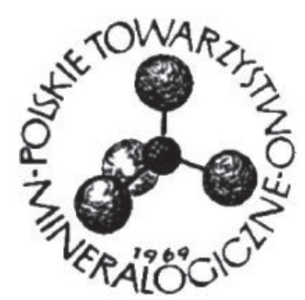

\title{
Developing teamwork skills in a course on ore deposits
}

\author{
Abigail K. Barker \\ Mineralogy, Petrology and Tectonics, Department of Earth Sciences, \\ Uppsala University, Villavägen 16, 75236 Uppsala, Sweden: Abigail. \\ barker@geo.uu.se
}

\begin{abstract}
Teamwork has distinct pedagogic advantages and is also an important transferable skill and the dominant mode of work graduates encounter in the workplace. However, students rarely become proficient in teamwork skills during their education. The goal was to test strategies to improve teamwork skills in a course on Ores deposits, MSc Earth Science, Uppsala University. A focus on teamwork was established by presenting the collaborative practicals as a series of linked opportunities to work together, get feedback on the teamwork process and reflect on and evaluate the teamwork. During the collaborative PBL sessions sociograms were used to provide feedback. Criteria based evaluation was also used to evaluate task oriented and interpersonal skills. Sociograms and criteria based evaluation promoted behavioural changes that improved teamwork interactions.
\end{abstract}

Keywords: teamwork; collaborative learning; real-time feedback; criteria based evaluation

mings et al. 2013). In collaborative learning social and cognitive aspects are interwoven (Dowell et al. 2020). The cognitive aspects are driven by social strategies and can be described by socio-cognitive skills that include sharing of and negotiating ideas, regulation of interactions and communication (Dowell et al. 2020). There are also six dimensions of communication integral to collaborative problem solving, namely participation, social impact, responsiveness, novelty, group cohesion and the extent of communication (Dowell et al. 2020).

Social cognitive theory also guides our understanding of behavioural change, because the cognitive, affective and behavioural domains are integrated in social learning settings (Bandura 2001; Eagly and Chaiken 1993). Attitudes are shaped by cognitive, affective and behavioural factors and drive behaviours (Bandura 2001; Kraus 1995). Social monitoring or raising awareness of 
behaviours is a pivotal step to changing behaviours and requires self-reflection and self-regulation (Bandura 2001; Dowell et al. 2020).

The literature on learning in teams highlights several essential aspects of instructional strategies for teamwork. Specific training in teamwork skills has been shown to benefit student achievements and promote collaboration (Riebe et al. 2016). Optimal training has been found to include both the skills and process of teamwork (Casper 2017; Fathi et al. 2019). Training is not only applicable to the students but also to facilitate the teacher's role in development of teamwork skills (O'Shea et al. 2013; Riebe et al. 2016). Teams commonly follow the Tuckman model as they progress through stages of formation and development (Riebe et al. 2016; Casper et al. 2017; Holen 2017). Tuckman proposed that teams develop through the stages of forming, storming, norming and performing (Tuckman 1965). Another crucial aspect of teamwork training is associated with giving and receiving feedback (Fathi et al. 2019). Course design is also imperative to education in teamwork skills; appropriate activities that require collaborative learning are required to be embedded in the programme along with the teamwork process (Riebe et al. 2016; Casper et al. 2017; Fathi et al. 2019). Feedback and assessment go hand in hand, self and peer feedback is considered to be a central input to the assessment and grading process, whereas Holen (2017) consider it part of the teamwork process (O'Shea et al. 2013; Riebe et al. 2016; Britton et al. 2017; Fathi et al. 2019).

I set out to investigate whether training in teamwork skills, effective course design, reciprocal feedback and criteria based evaluation can be combined into a successful strategy for teaching teamwork skills. Here, I present a systematic approach that encompasses these four aspects, and use social cognitive theory as a lens for explaining the social and behavioural outcomes.

\subsection{Characteristics of teamwork}

Effective teamwork is characterised by positive interdependence between individuals, equal responsibility and commitment amongst group members, co-management, group interaction and interpersonal skills ( $O$ 'Shea et al. 2013). There is a sense of sharing knowledge, responsibility and leadership which results in shared learning (O'Shea et al. 2013). However, suboptimal teamwork often develops when elements of fixed roles, delegation, competition, social loafing, dominating and diligent isolation occur (Pieterse and Thompson, 2010; O'Shea et al. 2013; Hsiung et al. 2014). Additionally, interpersonal problems can lead to unequal collaboration, whereas conflicts within effective teamwork can promote growth and learning (O'Shea et al. 2013).
Students concerns, such as group compositions, conflict resolution and challenges of multicultural settings, mostly stem from perceptions of unfair contributions to the task (Riebe et al. 2016; Fathi et al. 2019). These can be mitigated by co-creation and agreement to a team contract. Additionally, students perceive involvement in peer feedback as a suitable way to contribute to assessment (Riebe et al. 2016).

\section{Approach and implementation}

This case study focuses on a course in Ore and surficial deposits at Uppsala University, Sweden in September-October 2017. The scope of the course is 115 contact hours, ten students were participating in the course and the class was divided into two teams. The course is setup to focus on a separate ore deposit type each week. In 2017 the weeks were themed to cover VMS and SEDEX, MVT, Porphyry, Magmatic Ni-Cu-PGE and Iron oxide deposits (Table 1). For each ore deposit there were two practicals one on concepts and processes and a second case study. All practicals use real data and minimal instructions are given to foster problem-based learning (PBL) and teamwork. The teams were established to work on the 10 PBL sessions and the team seminar presentation amounting to 33 contact hours (Table 1). The $\mathrm{PBL}$ sessions and seminar presentations were then emphasised as connected opportunities to work together, give and receive feedback on the teamwork process and evaluate the teamwork.

The groups went through a 'forming' stage, where they chose team names, which led to a sense of identity and belonging to the team (Tuckman, 1965). Simultaneously the teams played an educational game to discover the global distribution of natural resources and economics of mining and wrote collaboration agreements (Riebe et al. 2016; Casper 2017). All team members were involved in constructing the collaboration agreement and everyone signed their respective agreements. The collaboration agreements aimed for self-management and addressed communication, plans for dealing with disagreements, expectations for contributions such as listening, providing their opinions, attendance, punctuality etc. (Bacon 2005; Maiden and Perry 2011).

A facilitator was present in all PBL sessions and was either the course director or a teaching assistant with a background in geology. The facilitators had both supervised the PBL practical sessions at least twice previously therefore they had intimate knowledge of the topic and data as well as experience of the previous sub-optimal teamwork.

The facilitator provided feedback on the teamwork using three different techniques: sociograms, spontaneous feedback and appointed times for feedback (Holen 2017; 
Table 1. Schedule for Ores and surficial deposits course autumn 2017

Teamwork activities include PBL sessions and the final seminar that are marked in bold italics.

\begin{tabular}{|c|c|c|c|}
\hline Day & Date & Time & Course content \\
\hline \multirow[t]{2}{*}{ Monday } & 28-Aug & $0900-1200$ & Intro to course $\&$ ore deposits \\
\hline & & $1300-1600$ & Ores in handspecimen \& core logging \\
\hline \multirow[t]{2}{*}{ Wednesday } & 30-Aug & $0900-1200$ & VMS+SEDEX deposits \\
\hline & & $1300-1600$ & VMS practical 1 \\
\hline \multirow[t]{2}{*}{ Friday } & 01-Sep & $1000-1200$ & Introduction to ore minerals \\
\hline & & $1300-1600$ & VMS practical 2 \\
\hline \multirow[t]{3}{*}{ Monday } & 04-Sep & 0900-1000 & Iron oxide mineralogy \\
\hline & & $1000-1200$ & ore mineral data \\
\hline & & $1300-1500$ & MVT \\
\hline \multirow[t]{2}{*}{ Wednesday } & 06-Sep & $1000-1200$ & MVT practical 1 \\
\hline & & $1300-1600$ & introduction to ore microscopy \\
\hline Thursday & 07-Sep & $1300-1700$ & ore microscopy \\
\hline \multirow[t]{2}{*}{ Friday } & 08-Sep & $0900-1200$ & MVT practical 2 \\
\hline & & $1300-1500$ & Physical properties of ore minerals \\
\hline \multirow[t]{2}{*}{ Monday } & 11-Sep & $1000-1200$ & Hydrothermal process of ore formation \\
\hline & & $1300-1500$ & porphyry deposits \\
\hline \multirow[t]{2}{*}{ Wednesday } & 13-Sep & $1000-1200$ & Exploration geochemistry \\
\hline & & $1300-1600$ & Porphyry practical 1 \\
\hline \multirow[t]{2}{*}{ Thursday } & 14-Sep & $1300-1500$ & ore microscopy \\
\hline & & $1500-1700$ & ore microscopy \\
\hline \multirow[t]{2}{*}{ Friday } & 15-Sep & $1000-1200$ & Exploration geophysics \\
\hline & & $1300-1600$ & Porphyry practical 2 \\
\hline \multirow[t]{2}{*}{ Monday } & 18-Sep & $1000-1200$ & Magmatic processes of ore formation + sulphide thermochemistry \\
\hline & & $1300-1400$ & Mineral and metal resource perspectives \\
\hline Tuesday & 19-Sep & $1000-1200$ & Magmatic Cu-Ni-PGE deposits \\
\hline \multirow[t]{2}{*}{ Wednesday } & 20-Sep & $0900-1200$ & CU-Ni-PGE practical 1 \\
\hline & & $1300-1700$ & ore microscopy \\
\hline Friday & 22-Sep & $1300-1600$ & CU-Ni-PGE practical 2 \\
\hline Monday & 25-Sep & $1100-1200$ & Mineral and metal resource perspectives \\
\hline \multirow[t]{2}{*}{ Tuesday } & 26-Sep & $1000-1200$ & Recycling \\
\hline & & $1300-1500$ & The ore mining environment \\
\hline \multirow[t]{2}{*}{ Wednesday } & 27-Sep & $1000-1200$ & Human impact on soil \\
\hline & & $1300-1500$ & Environmental impacts and remediation \\
\hline Thursday & 28-Sep & $0800-1700$ & Excursion \\
\hline \multirow[t]{2}{*}{ Friday } & 29-Sep & $1000-1200$ & Quaternary deposits \\
\hline & & $1300-1600$ & Sustainable resource management \\
\hline \multirow[t]{2}{*}{ Monday } & 02-Oct & $1000-1200$ & Iron oxide formation \& thermochemistry \\
\hline & & $1300-1600$ & Iron oxide thermometry \\
\hline \multirow[t]{2}{*}{ Tuesday } & 03-Oct & $1000-1200$ & Fe-oxide deposits \\
\hline & & $1300-1600$ & Fe-oxide practical 1 \\
\hline Wednesday & 04-Oct & $1000-1200$ & Mineral and metal resource perspectives 2 \\
\hline \multirow[t]{2}{*}{ Thursday } & 05-Oct & $1000-1200$ & Links between mesoscale and deposit scale \\
\hline & & $1300-1600$ & Fe-oxide practical 2 \\
\hline \multirow[t]{2}{*}{ Friday } & 06-Oct & $1000-1200$ & REE mineralisation \\
\hline & & $1300-1700$ & ore microscopy \\
\hline Monday & 09-Oct & $900-1200$ & Core logging \\
\hline Tuesday & 10-Oct & $1300-1700$ & ore microscopy \\
\hline Thursday & 19-Oct & $1300-1600$ & Ore deposits seminars \\
\hline
\end{tabular}


Holen and Sortland 2017; O'Shea et al. 2013). Sociograms are illustrations of a specific aspect of team communication and interaction over a specific duration, e.g. five minutes (Fig. 1; O'Shea et al. 2013). Sociograms are commonly composed of boxes labelled with participants names and arrows or tally marks measuring how much the individuals talked, asked or answered questions, eye contact between team members etc. The sociogram is then described to the team and an open question is used to stimulate the team to interpret the sociogram and discuss possible approaches to more balanced communication (Holen 2017; Holen and Sortland 2017). During the unfolding discussion the facilitator steps into the background and observes the process and implementation. Sociograms aim to promote behavioural change by providing opportunities for monitoring the social dynamics of the team and making the team aware of their interactions (Bandura 2001; Dowell et al. 2020). The discussion and interpretation encourage regulation of and between individuals and therefore provide a platform for behavioural change (Bandura 2001). It is important that sociograms are presented as observations without judgement, otherwise defensiveness will dominate over openness and prohibit monitoring (Bandura 2001; Holen 2017; Holen and Sortland 2017).

Sociograms can be used in addition to more traditional types of feedback such as spontaneous feedback or appointed time for feedback (Holen 2017; Holen and Sortland 2017). Feedback that focuses on the teamwork process such as the social-cognitive skills and dimensions of collaborative communication are the most effective at promoting reflection, regulation and monitoring that lead to behavioural change (Bandura 2001; Dowell et al. 2020). The objective of feedback is for the team to reflect and discuss the feedback and potential implementation of agreed strategies.

A reflection grid, based on ten criteria, was developed to help the students to evaluate and reflect upon their

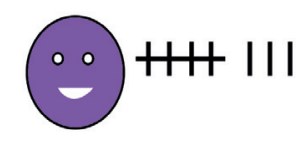

Rachel

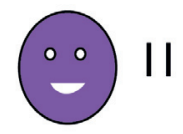

Adam

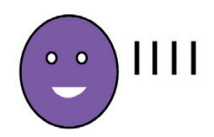

Matthew

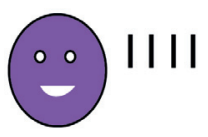

Laura teamwork skills and to identify actions to improve in future sessions (Table 2; Valentine et al. 2015; Strivens and Ward 2013; Britton et al. 2017). The reflection grid is divided into two aspects; firstly task oriented skills such as organisation, time management and monitoring progress. Secondly the team is encouraged to think about interpersonal skills like communication and active contribution. The two parts draw on the socio-cognitive and communication aspects of teamwork and the questions are aligned with key evaluation criteria (Strivens and Ward 2013; Valentine et al. 2015; Britton et al. 2017; Dowell et al. 2020). The form is summarised by two open questions asking the student to evaluate positive achievements and potential for development in the next teamwork session. The use of such criteria based evaluation aids reflection, which provides opportunities for behavioural change (Bandura 2001).

During the PBL sessions at least one type of feedback was given to each team every session. Each team received all three types of feedback over the course of a week, typically associated with two PBL sessions. The reflection grid was used on a weekly basis and at the end of the course to encourage the teams to evaluate the development of their teamwork skills throughout the entire course.

\section{Outcomes of the teamwork strategy}

An example sociogram represents a team of four students, whose names have been changed to protect their identities: Rachel, Matthew, Laura and Adam (Fig. 1). The facilitator observed their team interactions over 5 minutes and scribed tally marks for each time the individuals talked. The sociogram was presented to the students and the facilitator described the record of the observations. The team then discussed the sociogram in a friendly atmosphere and often identified with their contribution and how it compared to others. Following that they naturally expressed solutions such as 'I will speak up more' or 'I shall listen more' or 'We can pose more questions to include Adam'. Then they returned to the PBL session with immediate and tangible effects; the communication became balanced and Adam contributed more. The use of sociograms represents social monitoring as well as self- and co-regulation in action (Bandura 2001). The students identification with the observations shows the reflection and awareness that sociograms produce (Bandura 2001). The responses to the sociograms record the insights the students were coming to and the changes in communication after sociogram feedback indicate that they are effective tools for behavioural change allowing participants to test and adapt new behaviours in real time (Bandura 2001; Dowell et al. 2020).

Figure 1. Example sociogram. 
Table 2. Criteria employed for reflection.

Task oriented skills
Organization and planning
Implementation of the plan
Focus on the task
Time management and monitoring progress
All familiar with and can summarize the task

The impact of sociograms on the teamwork was evident even while the facilitator was a novice and easily became entangled in sharing the interpretations. It appeared challenging for the facilitator to simply present the observations and watch the process unfold. With more experience the facilitators mastered the process of describing observations and handing over to the teams. It was a steep learning curve for the facilitator to stimulate reflection without getting involved and withdraw to allow team development.

Feedback helps the teams to evaluate the balance in communication and social impact as well as regulating those bahaviours (Dowell et al. 2020). Therefore, the feedback encouraged informal reflection, which kept the atmosphere open and dynamic. Over time, as the team became familiar with discussing feedback, they built trust and became even more open to feedback, connecting with the group cohesion aspects of team communication (Dowell et al. 2020). Regular and cumulative changes in behaviour, teamwork and socio-cognitive skills were observed (Bandura 2001; Dowell et al. 2020). Participation and even attendance increased, due to the accountability recognised in the collaboration agreement and the increase in team spirit. This reflects the growth of group cohesion, participation, social impact and responsivity during the teamwork process as predicted by social cognitive theory (Bandura 2001; Dowell et al. 2020). The students developed a reflective mind set to evaluate their own contributions and the joint interplay of the team interactions, consistent with the findings of Strivens and Ward (2013). Additionally, the emphasis on teamwork and development of associated skills was noted as a strength in the course evaluation, reflecting the observations of Casper (2017). The feedback and criteria based evaluation encouraged many of the attributes of monitoring, regulation and reflection required to produce behavioural change (Bandura, 2001). They are also effective at emphasising the socio-cognitive and communication skills that are fundamental to learning in a collaborative setting (Dowell et al. 2020).
Interpersonal skills

Communication including resolution of disagreements

Decision making

All members have actively contributed

All members have shown responsibility and accountability

Accept and offer feedback

\section{Conclusions}

Following recommendations from the education research literature on teamwork, a teamwork component was integrated into a course on ore deposits. The teamwork component combined curriculum design with collaborative PBL at the core, training in teamwork skills, real-time feedback and criteria based evaluation. Real-time feedback and criteria based evaluation were found to be the most essential elements, because they target the social interactions of teamwork to raise awareness of interaction patterns and encourage self-reflection leading to behavioural change. In addition real-time feedback provided opportunities to directly try out different behaviours.

\section{Acknowledgements}

I would like to thank the students who participated in the course, as well as colleagues for encouragement and discussion. I am grateful to two anonymous reviewers whose constructive comments have helped develop this contribution.

\section{References}

Bacon, D. R. (2005). The effect of group projects on content-related learning. Journal of Management Education, 29(2), 248-267. DOI: 10.1177/1052562904263729

Bandura, A. (2001). Social cognitive theory: An agentic perspective. Annual review of psychology, 52(1), 1-26. DOI: 10.1111/1467-839X.00024

Britton, E., Simper, N., Leger, A., \& Stephenson, J. (2017). Assessing teamwork in undergraduate education: a measurement tool to evaluate individual teamwork skills. Assessment \& Evaluation in Higher Education, 42(3), 378-397. DOI: 10.1080/02602938.2015.1116497

Casper, W. C. (2017). Teaching beyond the Topic Teaching Teamwork Skills in Higher Education. Journal of Higher Education Theory and Practice, 17(6), 53-63.

Dowell, N. M., Lin, Y., Godfrey, A., \& Brooks, C. (2020). Exploring the Relationship between Emergent Sociocognitive Roles, Collaborative Problem-Solving Skills, and Outcomes: A Group Communication Analysis. Journal of Learning Analytics, 7(1), 38-57.

Eagly, A. H., \& Chaiken, S. (1993). The psychology of attitudes. Harcourt brace Jovanovich college publishers. 
Fathi, M., Ghobakhloo, M., \& Syberfeldt, A. (2019). An Interpretive Structural Modeling of Teamwork Training in Higher Education. Education Sciences, 9(1), 16. DOI: 10.3390/educsci9010016

Hemmings, A., Beckett, G., Kennerly, S., \& Yap, T. (2013). Building a community of research practice: Intragroup team social dynamics in interdisciplinary mixed methods. Journal of Mixed Methods Research, 7(3), 261273. DOI: $10.1177 / 1558689813478468$

Holen (2017) Interactive team work skills - some characteristics and functions. Interactive Teamwork Skills for the 21st century conference and workshop, Uppsala, Sweden

Holen and Sortland (2017) Teamwork indicator. An exercise for better team performance. Interactive Teamwork Skills for the 21st century conference and workshop, Uppsala, Sweden

Hsiung, C. M., Luo, L. F., \& Chung, H. C. (2014). Early identification of ineffective cooperative learning teams. Journal of Computer Assisted Learning, 30(6), 534-545.

Kraus, S. J. (1995). Attitudes and the prediction of behavior: A meta-analysis of the empirical literature. Personality and social psychology bulletin, 21(1), 58-75. DOI: $10.1177 / 0146167295211007$

Maiden, B., \& Perry, B. (2011). Dealing with free-riders in assessed group work: results from a study at a UK university. Assessment \& Evaluation in Higher Education, 36(4), 451-464. DOI: 10.1080/02602930903429302

O'Shea, N., Verzat, C., Raucent, B., Ducarme, D., Bouvy, T., \& Herman, B. (2013). Coaching tutors to observe and regulate leadership in PBL student teams or you can lead a horse to water but you can't make it drink.... Journal of Problem Based Learning in Higher Education, 1(1), 84-113.

Pieterse, V., \& Thompson, L. (2010). Academic alignment to reduce the presence of 'socialloafers' and 'diligent isolates' in student teams. Teaching in Higher Education, 15(4), 355-367. DOI: 10.1080/13562517.2010.493346

Riebe, L., Girardi, A., \& Whitsed, C. (2016). A systematic literature review of teamwork pedagogy in higher education. Small Group Research, 47(6), pp. 619-664. DOI: 10.1177/1046496416665221

Strivens, J., \& Ward, R. (2013). Reflection as a strategy to enhance students' engagement in their learning. The Student Engagement Handbook: Practice in Higher Education, 331.

Tuckman, B. W. (1965). Developmental sequence in small groups. Psychological bulletin, 63(6), 384.

Valentine, M. A., Nembhard, I. M., \& Edmondson, A. C. (2015). Measuring teamwork in health care settings: a review of survey instruments. Medical care, 53(4), e16-e30. DOI: 10.1097/MLR.0b013e31827feef6

Received: 14 October 2021

Accepted: 6 February 2022

Handling Editor: Jarosław Majka 